\title{
Tekrarlanan işlerde algılanan zihinsel iş yükü
}

\author{
Demet GÖNEN OCAKTAN ${ }^{*}$, Aslan Deniz KARAOĞLAN ${ }^{1}$, Alper AKÇA², \\ Ali ORAL ${ }^{3}$ \\ ${ }^{1}$ Balıkesir Üniversitesi, Mühendislik Fakültesi, Endüstri Mühendisliği Bölümü, Balıkesir, Türkiye \\ ${ }^{2}$ IŞBIR Elektrik Sanayi A.Ş., Balıkesir, Türkiye \\ ${ }^{3}$ Balıkesir Üniversitesi, Mühendislik Fakültesi, Makine Mühendisliği Bölümü, Balıkesir, Türkiye
}

Geliş Tarihi (Received Date): 16.04.2020

Kabul Tarihi (Accepted Date): 07.07.2020

$\ddot{O} \mathbf{z}$

Gün içerisinde gerçekleştirilen işlerin ă̆ırllğgl, tekrarlı ve sürekli olması çalışanları zorlamakta ve zamanla kas iskelet sistemi rahatsılılklarına yol açabilmektedir. Endüstride genelde işin yaratacağı fiziksel etkileri önlemek amacıyla çalışmalar yapılmaktadır. Ancak yapılan işlerin çalışanlara fiziksel etkilerinin yanında zihinsel etkileri de söz konusudur. Oluşabilecek performans ve verim kayıplarının önüne geçebilmek için hem fiziksel hem zihinsel iş yüklerini azaltacak iyileştirmelerin yapılması gereklidir. Bu çalışmada, alternatör üretiminde kullanılan stator sac kesim işlemi esnasında operatörlerin çalış̧ma duruşları ve zihinsel iş yükü incelenmiştir. Alternatör üretim süreci emek yoğun gerçekleştirilen işlerden birisidir. Stator sac kesim işleminde, çalışma duruşu değerlendirildiğinde çalışanın fiziksel olarak çok fazla zorlanmadığ d düşünülmektedir. Çalışma duruşunun ergonomik açıdan uygun olduğu düşünülse de gün içerisinde işin sürekli tekrarlanmasının çalışana fiziksel etkisinin yanında blkkinlık, isteksizlik ve iş motivasyonu düşüklüğ̈̈ gibi zihinsel etkilerinin de olabileceği düşünülmektedir. Yapılan işin çalı̧̧anda oluşturacağg zihinsel iş yükünü değerlendirmek için NASA-TLX yöntemi kullanılmıştır. Yöntemde önem ă̆ırllklarının belirlenmesinde ikili karşılaştırma süreci yer almaktadır. Bu süreçte belirsizlikler söz konusu olduğundan daha gerçekçi sonuçlar elde etmek üzere bulanık önceliklendirme metodu kullanılmıştır. Zihinsel işyükü boyutlarının ikili karşılaştırması sonucu elde edilen önem ağırlıklarının belirlenmesinde, iki akademisyen ve iki üretim yöneticisinin yer aldlğg bir ekibin değerlendirmelerinden yararlanılmıştır. Böylece daha objektif sonuçlar ortaya konulmuştur.

Anahtar kelimeler: Tekrarlanan işler, NASA-TLX yöntemi, bulanık önceliklendirme metodu.

\footnotetext{
* Demet GÖNEN OCAKTAN, dgonen@balikesir.edu.tr, https://orcid.org/0000-0003-1997-6719

Aslan Deniz KARAOĞLAN, deniz@balikesir.edu.tr; https://orcid.org/0000-0002-3292-5919

Alper AKÇA, tsr01@isbirelektrik.com.tr; https://orcid.org/0000-0002-2729-2635

Ali ORAL, alioral@balikesir.edu.tr, https://orcid.org/0000-0002-9144-3821
} 


\title{
Mental workload perceived in repetitive works
}

\begin{abstract}
The weight of the work done during the day, and the repetition and continuity, force the employees and may cause musculoskeletal disorders in time. In the industry, studies generally are carried out in order to prevent the physical effects of the work. However, the work done has physical effects as well as mental effects to the employees. Improvements are needed to reduce both physical and mental workloads are required to prevent performance and efficiency losses that may occur. In this study, the working postures and mental workload of the operators during the stator sheet cutting process used in alternator production were examined. Alternator production process is one of the labor intensive works. In the stator sheet cutting process, when the working stance is evaluated, it is thought that the employee is not having too much physical difficulty. Although it is thought that the working posture is ergonomically appropriate, it is thought that continuous repetition of work during the day may have physical effects on the employee, as well as mental effects such as boredom, unwillingness and low motivation of work. NASA-TLX method was used to evaluate the mental workload of the work done in the employee. NASA-TLX method was used to evaluate the mental workload of the job done in the employee. The method involves a binary comparison process in determining the importance weights. Fuzzy prioritization method has been used to obtain more realistic results since uncertainties are involved in this process. The evaluations of a team composed of two academicians and two production managers were used to determine the importance weights obtained as a result of the pairwise comparison of mental workload dimensions. Thus, more objective results have been revealed.
\end{abstract}

Keywords: Repeated works, NASA-TLX, fuzzy prioritization method.

\section{Giriş}

Gün içerisinde yapılan işler, aynı ya da benzer hareketlerin tekrarı ile gerçekleştiriliyorsa, bu işler tekrarlanan işler olarak tanımlanmakta ve insanlara hem fiziksel hem de zihinsel yük oluşturmaktadır. Çalışana etki eden yükün ağırlığı, yüke maruz kalma süresine ve sıklığına bağlı olarak değişen iş yükünün fiziksel güce bağlı olan kısmı fiziksel iş yükü ile ifade edilirken hesaplama, karar verme, hatırlama ve araştırma gibi zihinsel güce bağlı olan kısmı zihinsel iş yükü olarak ifade edilir. Hem fiziksel iş yükü hem de zihinsel iş yükü çalışanın sağlığını, performansını ve verimini, dolayısıyla da işin verimini etkiler [1-6].

Bir çalışanın kendisinden beklenilen bir işi uzun süre yapabilmesini sağlayacak zihinsel iş yükü seviyesini belirlemek, fiziksel iş yükü seviyesini belirlemekten daha zordur. Fiziksel iş yükünü çalışılan saat, üretilen miktar gibi performans kriterleri ile ölçebilirken, zihinsel iş yükünü ölçebileceğimiz bir metrik bulunmamaktadır [4].

Zihinsel iş yükü, fizyolojik ölçüm, subjektif ölçüm ve görev ölçümleri ile belirlenebilmektedir. Subjektif ölçüm teknikleri esnek olması, fazla zaman gerektirmemesi, ucuz olması ve sonuçlardaki hassasiyeti nedeniyle tercih edilmektedir. 
Subjektif ölçüm yöntemleri; Cooper-Harper Puanlama Ölçeği, Ardışık Karar Ölçütü, SWAT, Öznel İş Yükü Üstünlük Tekniği, Bedford Ölçütü, İş yükü profile, NASA İş Yükü İndeksi'dir. NASA-TLX yöntemi duyarlılık, seçicilik, güvenilirlik ve uygulama kolaylığı gibi özelliklerin tümünü içermektedir $[4,7]$.

Rahman ve Sen [8] yaptıkları çalışmada, tekrarlı hareketlerin iş tatmini, stres, performans ve sağlık üzerindeki etkilerini araştırmışlardır. İşinden memnun çalışanların performansının yüksek, memnun olmayan çalışanların performansının düşük olduğunu göstermişlerdir. Weber [9], Ford Motor Şirketinin hareket yakalama teknolojisini kullanarak montaj işlemlerinin benzetimlerini yaptıklarını ve böylece sürekli tekrar eden hareketlerin ergonomik etkilerini tahmin ederek, fiziksel olarak daha az stresli işler tasarladıklarını belirtmiştir. Bommer ve Fendley [10], tekrarlı işlerin bulunduğu imalat süreçlerinde, çalışanların zihinsel iş yükü kullanımını ayarlayarak çalışan performansını ve karlılığı arttırmak için bir yapı ortaya koymuşlardır. Mehta ve Agnew [11], tekrarlayan omuz çalışması sırasında zihinsel iş yükünün kas yorgunluğu üzerindeki etkisini araştırmışlardır. Zihinsel iş yükünün kas yorgunluğunu olumsuz yönde etkilediğini ve aynı zamanda fiziksel iş yükü ile etkileşim içerisinde olduğu sonucuna varmışlardır. Yener ve ark. [6], çalışmalarında işçilerin fiziksel ve zihinsel zorlanmalarını en küçüklemeyi aynı zamanda üretim miktarını en büyükleyecek iş rotasyonunu belirlemeyi amaçlamışlardır. Zihinsel zorlanmayı hesaplarken NASATLX yönteminden yararlanmışlardır.

Riono ve ark. [12] yaptıkları çalışmada, gemi personelinin zihinsel iş yükünün ölçümü için NASA TLX yöntemini bulanık mantık ile birleştirerek kullanmışlardır. Elde edilecek sonuçlardan görev süresinin ayarlanmasını, performansın iyileştirilmesini ve iş riskini azaltmayı hedeflemişlerdir. Eraslan ve ark. [13] yaptıkları çalışmada, bir fakültede görev yapan akademisyen, idari ve teknik personelin zihinsel iş yükünü geliştirdikleri bir ölçek ile değerlendirmişlerdir. Zihinsel iş yükünü belirlemek üzere kullanılan subjektif yöntemlerde ikili karşılaştırma yaparken gerçekçi sonuç vermesi için Bulanık AHP yönteminden yararlanmışlardır. Can [14] yaptığı çalışmada endüstriyel bir yelken firmasında zihinsel iş yükünü belirlemek için NASA-TLX yöntemini sezgisel bulanık küme teorisi ile birleştirerek sezgisel bulanık TLX yöntemini kullanmıştır.

$\mathrm{Bu}$ çalışmada, fiziksel olarak çalışanı zorlamayacağı düşünülen tekrarlı bir iş ele alınmıştır. İşin, yapılışı ve çalışma duruşu göz önünde bulundurulduğunda, ergonomik açıdan uygun olduğu düşünülse de tekrarlı ve sürekli olmasının yaratacağı zihinsel zorlanmanın ne düzeyde olacağı değerlendirilmek istenmiştir. Çalışmada zihinsel iş yükü ölçüm yöntemlerinden NASA-TLX yöntemi kullanılmıştır. Yöntemin altı boyutunun öncelik ağırlıklarının belirlenmesinde bulanık önceliklendirme metodu kullanılarak belirsizliği ortadan kaldırıp, daha gerçekçi sonuçların elde edilmesi amaçlanmıştır.

\section{Yöntem}

\subsection{NASA iş yükü indeksi}

NASA-TLX yöntemi, iş yükü seviyesini zihinsel gereksinim, fiziksel gereksinim, zamansal gereksinim, performans, çaba, rahatsızlık seviyesi olmak üzere altı alt boyut ışığında ortaya koyan etkili bir yöntemdir. $\mathrm{Bu}$ boyutların kısa açıklamaları ve 
değerlendirme aralıkları Tablo 1'de verilmiştir. Yöntemin hekimlerin [4, 15] ve hemşirelerin [16] zihinsel iş yüklerinin belirlenmesinde, üretim miktarını arttırmak üzere iş rotasyonu stratejisinin oluşturulmasında [6], gıda üretiminde çalışanlarda [17], engelli insanlar için teknoloji tabanlı yardımcı çözümlerde [18], artırılmış gerçeklik destekli öğrenme sistemi kullanarak katı geometrinin öğrenilmesinde [19], proje uzmanı seçiminde [20] ve E-ticaret sektöründe [21] gibi birçok uygulama örnekleri vardır.

Tablo 1. NASA-TLX bilişsel yük değerlendirme boyutları [4,22].

\begin{tabular}{|l|l|l|}
\hline Boyut & $\begin{array}{c}\text { Değerlendirme } \\
\text { Aralığı }\end{array}$ & Tanım \\
\hline $\begin{array}{l}\text { Zihinsel Gereksinim } \\
\text { MD:Mental Demand) }\end{array}$ & Düşük-Yüksek & $\begin{array}{l}\text { Yapılan iş esnasında (anlama, kavrama, düşünme, arama, karar } \\
\text { verme, hesaplama, hatırlama gibi faaliyetlere) ne kadar zihinsel } \\
\text { aktiviteye ihtiyaç duyulduğu ve işin kolay mı zor mu? Sade mi } \\
\text { karışı mı? olduğuna dair değerlendirme boyutu. }\end{array}$ \\
\hline $\begin{array}{l}\text { Fiziksel Gereksinim } \\
\text { (PD:Physical Demand) }\end{array}$ & Düşük-Yüksek & $\begin{array}{l}\text { Yapılan iş esnasında (itme, çekme, döndürme, kontrol etme, } \\
\text { çalıştırma gibi faaliyetlerde) ne kadar fiziksel aktiviteye ihtiyaç } \\
\text { duyulduğu ve işin kolay mı zor mu? yavaş mı hızlı mı? } \\
\text { olduğuna dair değerlendirme boyutu }\end{array}$ \\
\hline $\begin{array}{l}\text { Zamansal Gereksinim } \\
\text { (TD:Temporal }\end{array}$ & Düşük-Yüksek & $\begin{array}{l}\text { Yapılan iş esnasında zaman baskisı hissedilip hissedilmediğine, } \\
\text { ne kadar acele etmek zorunda kalındığına dair değerlendirme } \\
\text { boyutu. }\end{array}$ \\
\hline $\begin{array}{l}\text { Performans } \\
\text { (P: Performance) }\end{array}$ & İyi-Kötü & $\begin{array}{l}\text { Kişinin tamamladı̆̆ işle ilgili kendi performansından ne kadar } \\
\text { memnun kaldığına dair değerlendirme boyutu. }\end{array}$ \\
\hline $\begin{array}{l}\text { Çaba } \\
\text { (E: Effort) }\end{array}$ & Düşük-Yüksek & $\begin{array}{l}\text { İşi tamamlayana kadar zihinsel ve fiziksel olarak ne kadar çaba } \\
\text { gösterildiğine dair değerlendirme boyutu. }\end{array}$ \\
\hline $\begin{array}{l}\text { Rahatsızlık Seviyesi } \\
\text { (F: Frustration) }\end{array}$ & Düşük-Yüksek & $\begin{array}{l}\text { Iş esnasında ne kadar sinirli, güvensiz, isteksiz hissedildiğine } \\
\text { dair değerlendirme boyutu. }\end{array}$ \\
\hline
\end{tabular}

NASA-TLX yönteminde ilk aşamada, altı alt boyutun yapılan işe etkisi; "0 (düşük)", ile "100 (yüksek)" arasında ölçülendirilir (Şekil 1). Bu değerler ağırlıklandırılmamış iş yükü değerleridir [15].

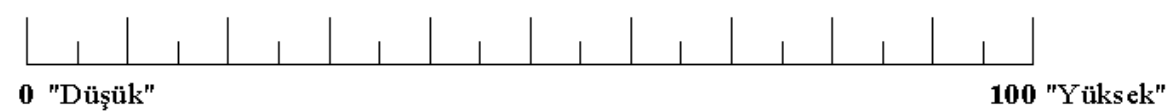

Şekil 1. İş yükü puanlama skalası.

Yöntemin zihinsel gereksinim boyutunda çalışanın işi yerine getirirken anlama, kavrama, karar verme gibi faaliyetleri değerlendirilirken, fiziksel gereksinim boyutunda ise işin "kolay mı-zor mu?" olduğu ve ne kadar fiziksel aktiviteye ihtiyaç duyulduğu belirlenmektedir. İş yerine getirilirken zaman kısıtının çalışma hızına ve çalışan psikolojisine etkisi değerlendirilmektedir. Aynı zamanda işin tamamlanma sürecinde çalışanın kendi performansını olumlu yada olumsuz olarak belirlemesi de performans olarak ortaya konulmaktadır. Çaba boyutunda, çalışanın iş ile ilgili zihinsel ve fiziksel olarak ne kadar çaba gösterdiği değerlendirilmektedir. Son boyut olan rahatsızlık seviyesi boyutunda ise çalışanın iş süresince isteksiz, sinirli, güvensiz hissetme durumları belirlenmektedir [6].

NASA-TLX'in ikinci aşaması altı alt boyutun kendi arasında ikili karşılaştırmasıdır (Tablo 2). Bu aşamada çalışan yaptığ 1 görevde, hangi boyutun diğer boyuta göre daha önemli olduğunu ya da kendisini daha çok zorladığını belirlemektedir. Her bir boyutun karşılaştırıldığı boyuta göre baskın gelmesi sıklık olarak değerlendirilmekte ve sıklık 
değer toplamı, toplam ikili karşılaştırma sayısına bölünerek her bir boyutun ağırlığı bulunmaktadır. En yüksek ağırlığa sahip boyut algılanan zihinsel iş yükünü en fazla etkisi olan boyuttur. Ağırlıklandırılmamış iş yükü değerleri, her bir boyutun ağırlığı ile çarpılarak, genel iş yükü indeksi (NASA-TLX) elde edilmektedir (Eş. 1).

Tablo 2. NASA-TLX ağırlıklandırma ölçeği.

\begin{tabular}{|l|l|}
\hline Zihinsel Gereksinim & Fiziksel Gereksinim \\
\hline Zamansal Gereksinim & Fiziksel Gereksinim \\
\hline Performans & Zihinsel Gereksinim \\
\hline Rahatsılık Seviyesi & Zamansal Gereksinim \\
\hline Efor & Performans \\
\hline Zamansal Gereksinim & Performans \\
\hline Efor & Zamansal Gereksinim \\
\hline Fiziksel Gereksinim & Efor \\
\hline Zihinsel Gereksinim & Zamansal Gereksinim \\
\hline Rahatsılık Seviyesi & Fiziksel Gereksinim \\
\hline Efor & Zihinsel Gereksinim \\
\hline Rahatsılık Seviyesi & Zihinsel Gereksinim \\
\hline Performans & Fiziksel Gereksinim \\
\hline Rahatsılık Seviyesi & Performans \\
\hline Rahatsılik Seviyesi & Efor \\
\hline
\end{tabular}

Zihinsel İş Yükü $=M D \times W M D+P D \times W P D+T D \times W T D+\mathrm{P} \times W \mathrm{P}+E \times W E+\mathrm{F} \times W \mathrm{~F}$

Burada;

MD, PD, TD, P, E, F algılanan iş yükünün altı boyutunu

$W_{x}: x \mathrm{MD}, \mathrm{PD}, \mathrm{TD}, \mathrm{P}, \mathrm{E}, \mathrm{F}$ olmak üzere algılanan iş yükünün her bir boyutuna ilişkin baskın olma sıklığını göstermektedir [6, 22].

Elde edilen zihinsel iş yükünün seviyesi 0-20 aralığında ise "çok düşük", 21-40 aralığında ise "düşük", 41-59 aralığında ise "orta", 60-79 aralığında ise "yüksek" ve 80100 aralığında ise "çok yüksek" olarak değerlendirilmektedir. Zihinsel iş yükünün yüksek olduğu çalışmalarda çalışanlara nasıl rahat ve konforlu bir çalışma ortamı yaratılabileceği düşünülmelidir [12].

Bulanık Önceliklendirme, klasik Analitik Hiyerarşi Prosesinin sözel ikili karşılaştırma matrislerindeki belirsizliği sayısallaştırarak en iyi sonucu belirleyen kriter ağırlıklarının bulunmasında kullanılmaktadır. Benzer bir yaklaşımla bu çalışmada NASA-TLX yönteminde alt boyutların ikişerli karşılaştırmalarındaki sözel belirsizliği sayısallaştırmak ve böylece en iyi sonucu belirleyen önem ağırlıklarını bulunması için Bulanık Önceliklendirme Metodundan yararlanılmıştır.

\subsection{Bulanık önceliklendirme metodu (BÖM)}

Bulanık önceliklendirme metodu (BÖM), amacın belirlendiği tanımlama aşaması, ikili karşılaştırmalar ile her bir kriterin ağırlıklarının belirlendiği analiz aşaması ve her kriterin önceliğinin belirlendiği karar aşamalarından oluşan bulanık analitik hiyerarşi prosesi (BAHP) yönteminin, ikinci aşamasında kriterlerin ağırlıklarının hesaplanmasında kullanılmaktadır. Bulanık önceliklendirme metodunda, amacın ve 
karar verme kriterlerinin belirlenmesinden sonra bulanık ikili karşılaştırma matrisleri oluşturulur ve karar kriterlerinin katsayıları matematiksel modelleme ile bulunur. Sonucun tutarlı olup olmadığına bakılarak karar verilir [23].

Bulanık önceliklendirme metodu Mikhailov ve Tsvetinov tarafından geliştirilmiştir ve alternatif hizmet sağlayıcıların değerlendirilmesinde [24], yeraltı mekanizasyon yöntemlerinin madende uygulanıp uygulanamayacağının değerlendirilmesinde [25], maden ocağında oluşabilecek tehlike ve riskleri önlemek amacıyla gerçekleştirilen FMEA (hata türleri ve etkileri analizi) çalışmasında [23], üniversite hastanesinde görev yapan hekimler üzerinde algılanan zihinsel iş yüklerinin değerlendirilebilmesinde [15] kullanılmıştır.

Bulanık önceliklendirme metodunda ikili karşılaştırma matrisleri (Eş. 2) bulanık mantık kurallarına göre oluşturulur. İki kriterin birbirlerine göre önem dereceleri belirlenirken bir alt sınır değeri $\left(l_{i j}\right)$, bir üst sınır değeri $\left(u_{i j}\right)$ ve bir de gerçekleşme olasılığı yüksek değer $\left(m_{i j}\right)$ belirlenir. Burada $w_{i}$ : i. kriterin önem katsayısını ifade etmektedir.

$\mathrm{D}=\left[\begin{array}{ccc}\frac{W_{1}}{W_{2}} & \ldots & \frac{W_{1}}{W_{n}} \\ \vdots & \ddots & \vdots \\ \frac{W_{n}}{W_{1}} & \cdots & \frac{W_{n}}{W_{n}}\end{array}\right]=\left[\begin{array}{ccc}1 & \left(l_{12}, m_{12}, u_{12}\right) \ldots & \left(l_{1 n}, m_{1 n}, u_{1 n}\right) \\ \left(l_{21}, m_{21}, u_{21}\right) & 1 & \left(l_{2 n}, m_{2 n}, u_{2 n}\right) \\ \left(l_{n 1}, m_{n 1}, u_{n 1}\right) & \left(l_{n 2}, m_{n 2}, u_{n 2}\right) & 1\end{array}\right]$

Karşılaştırmalarda Saaty'nin 9'lu ölçeği kullanılır. İkili karşılaştırma matrisi oluşturulduktan sonra BÖM ile karar verme kriterlerinin önem katsayıları bulanık ölçek (Tablo 3) kullanılarak bulunur [13]. Bulanık mantık kurallarına göre yapılan ikili karşılaştırmalarda, değerler aralıklarla verildiği için hata olasılığı azalacak ve daha doğru sonuçlara ulaşılabilecektir [23].

Tablo 3. İkili karşılaştırma için bulanık ölçek.

\begin{tabular}{|c|c|}
\hline Ölçek değeri & Bulanık sayı eşdeğeri \\
\hline 1 & $1,1,1$ \\
\hline 3 & $2 / 3,1,3 / 2$ \\
\hline 5 & $3 / 2,2,5 / 2$ \\
\hline 7 & $5 / 2,3,7 / 2$ \\
\hline 9 & $7 / 2,4,9 / 2$ \\
\hline
\end{tabular}

İkili karşılaştırmalarda Chang (1996) tarafından geliştirilen derece analizi yaygın olarak kullanılmaktadır. İlk olarak, karşılaştırma matrisinde her bir satırın bulanık toplamı (Eş. 3) ve daha sonra her bir sütunun toplamı bulunur (Eş. 4). Satır toplamları normalize edilir (Eş. 5).

$$
\begin{aligned}
& \sum_{j=1}^{m} M_{g_{i}}^{j}=\left(\sum_{j=1}^{m} l_{j}, \sum_{j=1}^{m} m_{j}, \sum_{j=1}^{m} u_{j}\right) \\
& \sum_{i=1}^{n} \sum_{j=1}^{m} M_{g_{i}}^{j}=\left(\sum_{i=1}^{n} l_{i}, \sum_{i=1}^{n} m_{i}, \sum_{i=1}^{n} u_{i}\right) \\
& S_{i}=\sum_{j=1}^{m} M_{g_{i}}^{j} \times\left[\sum_{i=1}^{n} \sum_{j=1}^{m} M_{g_{i}}^{j}\right]^{-1}
\end{aligned}
$$


Normalizasyonun ardından olabilirlik dereceleri (Eş. 6) hesaplanır ve diğer satırlar ile karşılaştırılarak minimum değer alınır (Eş. 7). Bu değerlerin birleştirilmesi ile ağırlık vektörü elde edilir (Eş. 8).

$V\left(S_{2} \geq S_{1}\right)=\mu_{M_{2}}(d)=\left\{\begin{array}{c}1, m_{2} \geq m_{1} \\ 0, l_{1} \geq u_{2} \\ \frac{l_{1}-u_{2}}{\left(m_{2}-u_{2}\right)-\left(m_{1}-l_{1}\right)}, \text { diğer }\end{array}\right\}$

$d^{\prime}\left(A_{i}\right)=\min V\left(S_{i} \geq S_{k}\right)$

$W^{\prime}=\left(d^{\prime}\left(A_{1}\right), d^{\prime}\left(A_{2}\right), \ldots, d^{\prime}\left(A_{n}\right)\right)^{T}$

A ̆̆ırlık vektörü Eş. 9 kullanılarak normalize edilir ve karar elemanlarına ait önem dereceleri bulunur [26].

$W=\left(d\left(A_{1}\right), d\left(A_{2}\right), \ldots, d\left(A_{n}\right)\right)^{T}$

\section{Uygulama}

Çalışma Balıkesir ilinde bulunan jeneratör ve alternatör üretimini gerçekleştiren İŞBİR Elektrik Sanayi A.Ş.' de yapılmıştır. Firmada alternatör üretim süreci değerlendirilmiş ve alternatörü oluşturan önemli parçalardan birisi olan stator için sac kesim işlemi ve bu işlemi gerçekleştiren operatörün çalışma duruşları ergonomik açıdan gözlenmiştir (Şekil 2). Bu işlem çalışan tarafından manuel olarak gerçekleştirilmekte ve sırasıyla kesilecek sacın alınıp prese yerleştirilmesi ve kesim işleminden sonra sacın alınıp paletin üzerine konulması işlemlerinden oluşmaktadır. Stator sac kesim işlemi esnasında; çalışan oturarak çalışmaktadır. Sandalye ve tezgah yüksekliği ergonomik standartlar açısından uygundur. Kullanılan pres, teknoloji açısından eski olduğu için sesli çalışmaktadır ve ses seviyesi 103 dBA'dır. Çalışan, kişisel koruyucu olarak kulaklık takmaktadır Çalışan, sacın prese yerleştirilmesi ve presten alınıp palete dizilmesi esnasında dönme hareketini kısmen sandalyede dönerek kısmen de vücudunu hafif burarak yapmaktadır. Yapılan iş ilk bakıldığında çalışanı fiziksel olarak zorlamayacak bir iş olarak değerlendirilmektedir. Ancak işin sürekli ve tekrarlı olduğu dikkate alındığında çalışanı fiziksel olarak çok fazla olmasa da zorlayacaktır. Fiziksel olarak çok fazla zorlanma yaratmayacağı değerlendirilen ancak; sürekli ve tekrarlı olarak, aynı zamanda sesli bir ortamda gerçekleştirilen bu işlemin çalışanı zihinsel olarak zorlayacağı düşünülmüştür. Çalışanda oluşacak zihinsel iş yükünü belirlemek üzere NASA-TLX yöntemi kullanılmıştır. 


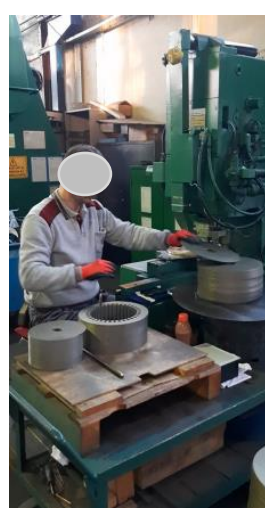

a.sacın alınması

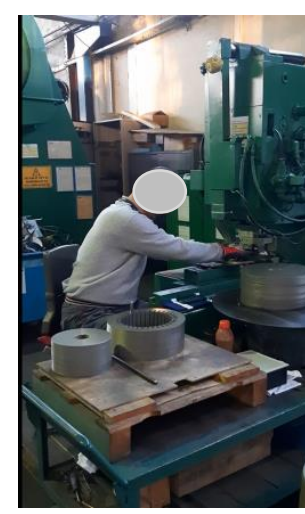

b.sacin makineye yerleştirilmesi

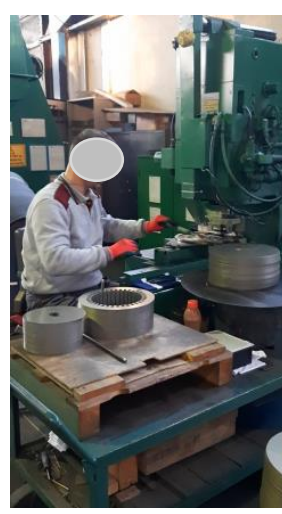

c.sacın makineden alınması

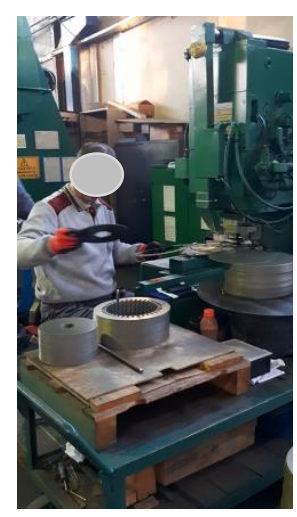

d.sacin palete dizilmesi

Şekil 2. Stator sac kesim işlem süreci.

Çalışana yöntemin ilk aşamasını oluşturan altı boyut açıklanmıştır. Yaptığı işte ne kadar zihinsel aktiviteye ve fiziksel aktiviteye ihtiyaç duyduğu, zaman baskısı hissedip hissetmediği, performansından ne kadar memnun kaldığ 1 , zihinsel ve fiziksel olarak ne kadar çaba gösterdiği ve sinirli, güvensiz, isteksiz hissedip hissetmediğini 0 (düşük) ile 100 (yüksek) arasında puanlaması istenmiştir. Çalışanın altı boyut için puanlaması Tablo 4'de verilmiştir.

Tablo 4. Çalışanın zihinsel iş yükü faktör puanları.

\begin{tabular}{|l|c|}
\hline & Stator Sac Kesim Operatörü \\
\hline Zihinsel Talep & 70 \\
\hline Fiziksel Talep & 85 \\
\hline Zamansal Talep & 70 \\
\hline Performans & 75 \\
\hline Çaba/Efor & 75 \\
\hline Rahatsılılk Seviyesi & 30 \\
\hline
\end{tabular}

Tablo 4'e bakıldığında, verilen puanların bazı boyutlar için biraz yüksek/düşük olduğu düşünülmüştür. Bunun nedeni olarak, insanların kendi yaptıkları işleri diğer işlerden önemli görmeleri ve işlerini yerine getirirken en çok kendilerinin zorlandıklarını ve emek harcadıklarını düşünmeleri olabileceğine karar verilmiştir. Objektif bir değerlendirme sağlayabilmek amacıyla zihinsel iş yükü hesaplanırken NASA-TLX yönteminde ikili karşılaştırmalar için, iki akademisyen ve iki üretim yöneticisinin değerlendirmeleri alınmıştır. Akademisyen ve üretim yöneticilerine ait ikili karşılaştırma matrisleri en çok tekrarlanan puanlar dikkate alınarak birleştirilmiştir İkili karşılaştırma matrisinin (Eşitlik 2) oluşturulmasında, kriterlerin birbirlerine göre üstünlükleri belirlenirken Bulanık AHP yöntemi kullanılmıştır. Uzman ekip tarafından oluşturulan ikili karşılaştırma matrisi üçgensel üyelik fonksiyonu (Tablo 3) ile bulanıklaştırılmış ve Tablo 5'de verilmiştir. 
Tablo 5. Bulanık ikili karşılaştırma matrisi.

\begin{tabular}{|l|c|c|c|c|c|c|}
\hline & Zihinsel & Fiziksel & Zamansal & Performans & Çaba/Efor & Rahatsıllk \\
\hline Zihinsel Talep & $1,1,1$ & $2 / 7,1 / 3,2 / 5$ & $2 / 3,1,3 / 2$ & $2 / 3,1,3 / 2$ & $2 / 3,1,3 / 2$ & $2 / 5,1 / 2,2 / 3$ \\
\hline Fiziksel Talep & $5 / 2,3,7 / 2$ & $1,1,1$ & $3 / 2,2,5 / 2$ & $3 / 2,2,5 / 2$ & $3 / 2,2,5 / 2$ & $2 / 3,1,3 / 2$ \\
\hline Zamansal Talep & $2 / 3,1,3 / 2$ & $2 / 5,1 / 2,2 / 3$ & $1,1,1$ & $2 / 3,1,3 / 2$ & $2 / 3,1,3 / 2$ & $2 / 3,1,3 / 2$ \\
\hline Performans & $2 / 3,1,3 / 2$ & $2 / 5,1 / 2,2 / 3$ & $2 / 3,1,3 / 2$ & $1,1,1$ & $2 / 3,1,3 / 2$ & $2 / 3,1,3 / 2$ \\
\hline Çaba/Efor & $2 / 3,1,3 / 2$ & $2 / 5,1 / 2,2 / 3$ & $2 / 3,1,3 / 2$ & $2 / 3,1,3 / 2$ & $1,1,1$ & $2 / 5,1 / 2,2 / 3$ \\
\hline Rahatsızlık Seviyesi & $3 / 2,2,5 / 2$ & $2 / 3,1,3 / 2$ & $2 / 3,1,3 / 2$ & $2 / 3,1,3 / 2$ & $3 / 2,2,5 / 2$ & $1,1,1$ \\
\hline
\end{tabular}

Yöntemde ağırlıkların belirlenmesi aşamasında bulanık önceliklendirme yönteminden yararlanılmıştır.

İlk aşamada, Tablo 5'de elde edilen bulanık ikili karşılaştırma matrisinde yer alan her bir satırın bulanık toplamı hesaplanır (Örneğin, zihinsel boyut için = $1+2 / 7+2 / 3+2 / 3+2 / 3+2 / 5=3.69)$. Bulanık satır toplamlarından sonra her bir sütunun toplamı bulunur $\left(\sum l=3.69+8.67+4.07+4.07+3.80+.6 .00=30.30\right)$. Satır toplamları normalize edilir.

$$
\begin{array}{lll}
\text { S }_{\text {Zihinsel }} & =(3.69 ; 4.83 ; 6.57) \times(1 / 52.73 ; 1 / 39.83 ; 1 / 30.30)=(0.069 ; 0121 ; 0.216) \\
S_{\text {Fiziksel }} & =(8.67 ; 11.00 ; 13.50) \times(1 / 52.73 ; 1 / 39.83 ; 1 / 30.30)=(0.164 ; 0.276 ; 0.445) \\
S_{\text {Zamansal }} & =(4.07 ; 5.50 ; 7.67) \times(1 / 52.73 ; 1 / 39.83 ; 1 / 30.30)=(0.077 ; 0.138 ; 0.253) \\
S_{\text {Performans }} & =(4.07 ; 5.50 ; 7.67) \times(1 / 52.73 ; 1 / 39.83 ; 1 / 30.30)=(0.077 ; 0.138 ; 0.253) \\
S_{\text {Çaba/Efor }} & =(3.80 ; 5.00 ; 6.83) \times(1 / 52.73 ; 1 / 39.83 ; 1 / 30.30)=(0.072 ; 0.125 ; 0.225) \\
S_{\text {Rahatsılık }} & =(6.00 ; 8.00 ; 10.50) \times(1 / 52.73 ; 1 / 39.83 ; 1 / 30.30)=(0.113 ; 0.200 ; 0.346)
\end{array}
$$

ve normalizasyon işleminin ardından olabilirlik dereceleri hesaplanır.

$$
\begin{array}{lllll}
\mathrm{V}(\mathrm{SZ} \geq \mathrm{SF})=0.255 & \mathrm{~V}(\mathrm{SZ} \geq \mathrm{SZa})=0.892 & \mathrm{~V}(\mathrm{SZ} \geq \mathrm{SP})=0.892 & \mathrm{~V}(\mathrm{SZ} \geq \mathrm{Sç})=0.967 & \mathrm{~V}(\mathrm{SZ} \geq \mathrm{SR})=0.563 \\
\mathrm{~V}(\mathrm{SF} \geq \mathrm{SZ})=1.000 & \mathrm{~V}(\mathrm{SF} \geq \mathrm{SZa})=0.392 & \mathrm{~V}(\mathrm{SF} \geq \mathrm{SP})=1.000 & \mathrm{~V}(\mathrm{SF} \geq \mathrm{Sç})=1.000 & \mathrm{~V}(\mathrm{SF} \geq \mathrm{SR})=1.000 \\
\mathrm{~V}(\mathrm{SZa} \geq \mathrm{SZ})=1.000 & \mathrm{~V}(\mathrm{SZa} \geq \mathrm{SF})=0.392 & \mathrm{~V}(\mathrm{SZa} \geq \mathrm{SP})=1.000 & \mathrm{~V}(\mathrm{SZa} \geq \mathrm{SC})=1.000 & \mathrm{~V}(\mathrm{SZa} \geq \mathrm{SR})=0.688 \\
\mathrm{~V}(\mathrm{SP} \geq \mathrm{SZ})=1.000 & \mathrm{~V}(\mathrm{SP} \geq \mathrm{SF})=0.292 & \mathrm{~V}(\mathrm{SP} \geq \mathrm{SZa})=1.000 & \mathrm{~V}(\mathrm{SP} \geq \mathrm{SÇ})=1.000 & \mathrm{~V}(\mathrm{SP} \geq \mathrm{SR})=0.688 \\
\mathrm{~V}(\mathrm{SCC} \geq \mathrm{SZ})=1.000 & \mathrm{~V}(\mathrm{SC} \geq \mathrm{SF})=0.292 & \mathrm{~V}(\mathrm{SC} \geq \mathrm{SZa})=0.925 & \mathrm{~V}(\mathrm{SCC} \geq \mathrm{SP})=0.925 & \mathrm{~V}(\mathrm{SÇ} \geq \mathrm{SR})=0.599 \\
\mathrm{~V}(\mathrm{SR} \geq \mathrm{SZ})=1.000 & \mathrm{~V}(\mathrm{SR} \geq \mathrm{SF})=0.709 & \mathrm{~V}(\mathrm{SR} \geq \mathrm{SZa})=1.000 & \mathrm{~V}(\mathrm{SR} \geq \mathrm{SP})=1.000 & \mathrm{~V}(\mathrm{SR} \geq \mathrm{SC \zeta})=1.000
\end{array}
$$

Hesaplanan olabilirlik derecelerine göre elde edilen matriste, satırların en küçük değeri alınarak ağırlık vektörü elde edilir.

$\mathrm{W}^{\prime}=(0.255 ; 1 ; 0.392 ; 0.392 ; 0.292 ; 0.709)$

Son aşamada ağırlık vektörü normalize edilir ve altı boyutun önem ağırlıkları belirlenir.

$\mathrm{W}=(0.08 ; 0.33 ; 0.13 ; 0.13 ; 0.10 ; 0.23)$

NASA-TLX-BÖM=70 $\times(0.08)+85 \times(0.33)+70 \times(0.13)+75 \times(0.13)+75 \times(0.10)+30 \times(0.23)=66.73$

Ekip tarafından belirlenen önem ağırlıklarına ve çalışan tarafından belirlenen faktör puanlarına göre, stator sac kesim operatörünün zihinsel iş yükü \%66.73 olarak hesaplanmıştır. Çalışanın üzerindeki zihinsel iş yükü "Yüksek" tir. Zihinsel iş yükünü en fazla "fiziksel gereksinim" ve "rahatsızlık seviyesi" nin etkilediği görülmektedir. 


\section{Sonuç}

$\mathrm{Bu}$ çalışma, İŞBİR Elektrik Sanayi ve A.Ş.'nin üretim süreçlerinde iyileştirmeler yapmak üzere, çalışan üzerinde oluşan zihinsel iş yükünün belirlenmesi ve risk oluşturabilecek işlerin ve iş ortamlarının yeniden düzenlenmesi amaciyla gerçekleştirilmiştir. Üretim süreçleri değerlendirilerek belirlenen stator sac kesim işinin yapılışı ve çalışanın çalışma esnasındaki çalışma duruşu, ergonomik açıdan uygun görülmüş ve fiziksel açıdan çalışanı çok fazla zorlamayacağı düşünülen bu işin, çalışanda zihinsel yük oluşturup oluşturmayacağı araştırılmıştır. İşin seçilme nedenlerinden bir diğeri de mesai saati süresince tekrarlanmasıdır. Tekrarlanan iş olması nedeniyle çalışanda ileride kas iskelet sistemi rahatsızlığı oluşturma ihtimali verilen yeterli sayıdaki molalarla önlenmeye çalışılmıştır. Ancak gün boyu aynı işlemin tekrarlanması çalışanda yorgunluk ve monotonluk nedeniyle isteksizlik yaratabilmektedir.

Çalışanda algılanan zihinsel iş yükünü belirlemek için, NASA-TLX yönteminden yararlanılmıştır. Çalışandan yaptığı işi düşünerek yöntemde yer alan altı boyutu değerlendirmesi istenmiştir. Zihinsel iş yükü değerlendirilirken boyutlar arasında yapılan ikili karşılaştırmalar sonucu elde edilen önem ağırlıklarının belirlenmesi aşamasında uzman görüşleri alınmış ve karşılaştırma işleminde bulanık önceliklendirme metodu kullanılmıştır. NASA-TLX-BÖM sonucunda zihinsel iş yükünü en fazla "fiziksel gereksinim" in ve "rahatsızlık seviyesi" in, en az da "zihinsel gereksinim" in etkilediği sonucuna varılmıştır. Fiziksel gereksinimin yüksek bulunmasının nedeni, çalışanın sacı alıp makineye yerleştirmesi, makineyi çalıştırması, makineyi durdurup, sacı alıp tezgaha koyması gibi faaliyetlerin gün boyu tekrarlanması ve bu işlemler esnasında sürekli oturması, hareketsiz kalmasıdır. Rahatsızlık seviyesinin yüksek bulunmasının nedeni olarak, işin yapılması sürecinde tekrarlı olması nedeniyle bıkkınlık, isteksizlik ve belli bir miktarda sac kesmeye çalışmasının yaratacağı gerginlik vb. gibi faktörlerin olacağı düşünülmektedir. Stator kesim işlemi anlama, kavrama, düşünme, arama, karar verme, hesaplama, hatırlama gibi faaliyetleri çok fazla içermediği için zihinsel gereksinim en az etkileyen faktör olarak bulunmuştur.

Çalışanda oluşan zihinsel iş yükünü ve az da olsa fiziksel iş yükünü ortadan kaldırabilmek amacıyla; stator sac kesim işleminin öncesinde ve sonrasında emek yoğun gerçekleştirilen rotor ve rondel sac kesim işlemlerinin de gerçekleştirileceği bir makinenin tasarımının yapılması önerilmiştir. Tasarım çalışmaları devam etmektedir.

\section{Teșekkür}

$\mathrm{Bu}$ çalışmanın gerçekleştirilebilmesini mümkün kılan İŞBİR Elektrik Sanayi A.Ş'ye teşekkür ederiz. Ayrıca katkılarından dolayı Öznur ALKAN'a teşekkür ederiz.

\section{Kaynakça}

[1] Atik, E. ve Akoğlan, M. K., İş Yükü Algısı ve İş Yükünün İnsan Kaynakları Yönetiminde Kullanımı: Eskişehir'de Otel İşletmeleri Örneği, Anadolu Üniversitesi Sosyal Bilimler Dergisi, 16, 5, 341-366, (2016). 
[2] Çetinkaya, F. ve Baykent, G., İşyeri Çalışma Ortamı Koşullarının Ergonomik Yönden İncelenmesi (Örnek: Şekerleme Firmas1), Uşak Üniversitesi Fen ve Doğa Bilimleri Dergisi, 1, 1, 15-31, (2017).

[3] Dağdeviren, M., Eraslan, E. ve Kurt, M., Çalışanların Toplam İş Yükü Seviyelerinin Belirlenmesine Yönelik Bir Model Ve Uygulaması, Journal of the Faculty of Engineering and Architecture of Gazi University, 20, 4, 517525, (2005).

[4] Kılıç, E. D., Acil Servis Hekimlerinin NASA-RTLX Yöntemi İle Zihinsel İş Yüklerinin Değerlendirilmesi: Bir Uygulama Çalışması, Atatürk Üniversitesi İktisadi ve İdari Bilimler Dergisi, 30, 3, 645-662, (2016).

[5] Ordukaya, H., Fiziksel İş Yükü ve Ergonomi, Anahtar Dergisi, 273-274, 42-47, (2011).

[6] Yener, Y., Can, G. F. ve Toktaş P., Fiziksel Zorlanma ve Algilanan İş Yükü Düzeylerini Dikkate Alan Bir İş Rotasyonu Önerisi, Eskişehir Osmangazi Üniversitesi Mühendislik ve Mimarlık Fakültesi Dergisi, 27, 1, 8-18, (2019).

[7] Yağmuroğlu, Z., Günaydın, H.M. ve Kale, S., İş Gereksinim Analizi Yönteminin İş Güvenliği Bağlamında İncelenmesi, 3. İşçi Sağlığı ve İş Güvenliği Sempozyumu, 195-200, Çanakkale, (2011).

[8] Rahman, M. ve Sen, A. K., Effect of job satisfaction on stress, performance and health in self-paced repetitive work, International Archives Occupational Environmental Health, 59, 2, 115-121, (1987).

[9] Weber, A., Ergonomics: Ford Simulates, (2008) https://www.assemblymag.com/articles/86145-ergonomics-ford-simulates, (07.01.2020)

[10] Bommer, S. C. ve Fendley, M., A theoretical framework for evaluating mental workload resources in human systems design for manufacturing operations, International Journal of Industrial Ergonomics, 63, 7-17, (2018).

[11] Mehta, R. K. ve Agnew, M. J., Effects of physical and mental demands on shoulder muscle fatigue, Work, 41, 2897-2901, (2012).

[12] Riono, Suparno ve Bandono, A., Analysis of Mental Workload With Integrating Nasa TLX and Fuzzy Method, International Journal of ASRO, 1, 1, 37-45, (2018).

[13] Eraslan, E., Can, G. F. ve Atalay, K. D., Mental Workload Assessment Using A Fuzzy Multi-Criteria Method, Tehnički vjesnik, 23, 3, 667-674, (2016).

[14] Can, G.F., Intituionistic Fuzzy TLX (IF-TLX): Implementation Of Intituionistic Fuzzy Set Theory For Evaluating Subjective Workload, Journal of Turkish Operations Management, 2, 1, 79-90, (2018).

[15] Emeç, Ş. ve Akkaya, G., Sağlık Sektöründe Zihinsel İş Yükü Değerlendirmesi Ve Bir Uygulama, Ergonomi, 1, 3, 156-162, (2018).

[16] Karadağ, M., Cankul, İ. H., Hemşirelerde Zihinsel İş Yükü Değerlendirmesi, Anadolu Hemşirelik ve Sağlık Bilimleri Dergisi, 18, 1, 26-34, (2015).

[17] Mamak, E. B. E. ve Can, G. F., Algılanan İş Yükü ve Çalışma Duruşları Dikkate Alınarak Operatörlerin Ergonomik Risk Düzeylerinin Çok Kriterli Karar Verme Yaklaşımı İle Değerlendirilmesi, Ergonomi, 1, 2, 77-91, (2018).

[18] Riccio, A., Leotta, F., Bianchi, L., Aloise, F., Zickler, C., Hoogerwerf, E-J., Kübler, A., Mattia, D. ve Cincotti, F., Workload measurement in a communication application operated through a P300-based brain-computer interface, Journal of Neural Engineering, 8, 2, 37-46, (2011). 
[19] Lin, H. C. K., Chen, M. C. ve Chang, C. K., Assessing the effectiveness of learning solid geometry by using an augmented reality-assisted learning system, Journal Interactive Learning Environments, 23, 6, 1-12, (2013).

[20] Şeker, A., Using Outputs of NASA-TLX for Building a Mental Workload Expert System, Gazi University Journal of Science, 27, 4, 1131-1142, (2014).

[21] Soenandi, I. A., Christy, L. ve Ginting, M., Work Performance Measurement of Data Entry Employees in E-Commerce Industry Based on Mental Workload Value, Computer, Mathematics and Engineering Applications, 10, 2, 67-73, (2019).

[22] Mouzé-Amady, M., Raufaste, E., Prade, H. ve Meyer, J.-P., Fuzzy-TLX: using fuzzy integrals for evaluating human mental workload with NASA-Task Load indeX in laboratory and field studies, Ergonomics, 56, 5, 752-763, (2013).

[23] Özfırat, P. M., Bulanık Önceliklendirme Metodu Ve Hata Türü Ve Etkileri Analizini Birleştiren Yeni Bir Risk Analizi Yöntemi, Journal of the Faculty of Engineering and Architecture of Gazi University, 29, 4, 755-768, (2014).

[24] Mikhailov, L. ve Tsvetinov, P., Evaluation of services using a fuzzy analytic hierarchy process, Applied Soft Computing, 5, 1, 23-33, (2004).

[25] Özfirat, M. K., A Fuzzy Method for Selecting Underground Coal Mining Method Considering Mechanization Criteria, Journal of Mining Science, 48, 3, 533-544, (2012).

[26] Ülker, S. N., İnsan Kaynaklarında Bulanık AHP Destekli Yetenek Yönetimi İle Liderlerin Belirlenmesi, Yüksek Lisans Tezi, Sakarya Üniversitesi, Fen Bilimleri Enstitüsü, Sakarya, (2019). 